\title{
Controversial topics in the management of displaced supracondylar humerus fractures in children
}

\author{
Juan Pretell-Mazzini · Juan Rodriguez-Martin • \\ Ismael Auñon-Martin · José Alberto Zafra-Jimenez
}

Received: 23 January 2011 / Accepted: 9 July 2011 / Published online: 22 July 2011

(C) The Author(s) 2011. This article is published with open access at Springerlink.com

\begin{abstract}
The aim of our study was to review the literature looking for the up to date information regarding these controversial topics. An electronic literature search was performed using the Medline/PubMed database. A closed reduction attempt should always be done first. It is more important to engage both columns as well as divergence of the pins no matter whatever configuration is applied. Time to surgery seems to be not an important factor to increase the risk of complications as well as open reduction rate. Usually neurological injuries present a spontaneous recovery. If there is absent pulse, we should follow the algorithm associated with the perfusion of the hand.
\end{abstract}

Keywords Closed reduction · Pin configuration . Vascular injury - Supracondylar humerus fracture . Children

\section{Introduction}

Supracondylar humerus fractures (SCHF) are common pediatric injuries [1-5] representing about $3 \%$ of all fractures $[5,6]$, being the most common elbow fractures in children $[7,8]$.

The mean age ranges between 5 and 7 years old, representing the most frequent fracture in children under 8 years of age $[1,9,10]$. Boys have had a higher incidence

J. Pretell-Mazzini $(\bowtie) \cdot$ I. Auñon-Martin · J. A. Zafra-Jimenez Orthopedic Surgery Department, 12 de Octubre Hospital, Avd. De Córdoba s/n, 28041 Madrid, Spain

e-mail: el_giova23@yahoo.com

J. Rodriguez-Martin

Trauma and Orthopedic, Shoulder and Elbow Unit, Infanta Leonor Hospital, C/Gran Vía del Este 80, 28031 Madrid, Spain of this type of fracture, but the difference in comparison with girls seems to be equalizing, and higher rates in girls have actually been reported in some series [7].

The mechanism is usually due to a fall onto outstretched hand with the elbow in full extension (97-99\% of cases), the olecranon engages the olecranon fossa and acts as a fulcrum, while the anterior aspect of the capsule provides a tensile force on the distal part of the humerus proximal to its insertion [7].

These fractures are classified using the modified Gartland classification [11], and most of them are of extension type [5].

Displaced SCHF are challenging injuries to treat $[5,12$, 13] and entail technically difficult procedures for orthopedics surgeons [9]. There remains controversy in the literature with regards to some topics in the definitive management of these types of fractures [14, 15].

These topics could be grouped into: method of reduction (open vs. closed), constructs for stabilization of the fractures and impact of time to surgery in complications. The aim of our study is to review the literature looking for the up to date information regarding these topics.

\section{Materials and methods}

An electronic review of the literature was performed to identify publications dealing with those controversial topics. Pubmed/Medline database was used and only English language articles were included.

As a result, we found seven (7) articles (Table 1) dealing with the comparison between these two types of techniques. There were three (3) articles [1, 2, 9] in which the comparison was done between closed reduction and primary open reduction (no closed reduction attempt performed) and in the other four (4) articles [3, 4, 6, 13], it was 
with a secondary open reduction (open reduction after closed reduction attempts).

Biomechanical as well as clinical studies (Table 2) were found dealing with pin configurations used for stabilization of these fractures. The main biomechanical studies were the ones performed by Zionts et al. [16], Lee et al. [17] and Larson et al. [18]. Clinical studies such as the ones conducted by Foead et al. [19], Kocher et al. [20], Tripuraneni et al. [21], Eberhardt et al. [22] and Slongo et al. [23] were also included.

There were five (05) retrospective studies [24-28] regarding the impact of time to surgery in complications (Table 3). The cutoff time used was between 8 and $12 \mathrm{~h}$.

Due to the heterogeneous nature of the articles dealing with the method of reduction as well as the construct for stabilization and the low level of evidence; we feel that it will be not accurate to perform a statistical analysis of the retrieved data.

However, the articles dealing with the impact of time to surgery in complications have a more homogenous behavior. The main outcome parameters were well described with enough data to perform statistical analysis.

Articles were also classified according to their level of evidence following the grading system proposed by Sackett [29]. There are five levels of evidence: level I (systematic reviews of level I studies, randomised trial, meta-analysis); level II (prospective cohort studies, systematic review of level II studies); level III (case control studies, retrospective cohort study, systematic review of level III studies); level IV (case series) and level $\mathrm{V}$ (expert opinion).

Statistical analysis

A meta-analysis was performed using the fixed-effects model in the meta-statistical package in STATA v.10.0 (Stata Corp., College Station, Texas) because heterogeneity was measured by means of $I^{2}$ statistic proposed by Higgins and Thompson [30]. Combined odds ratio (OR) was weighted by the inverse variance; Mantel-Haenszel estimates were calculated across individual studies.

\section{Results}

Twenty articles were identified after our searches and used in the analysis $[1-4,6,9,13,16-28]$.

Method of reduction

The studies included were level III of evidence [1, 3, 4, 6, 9, 13] except one [2] that was a level I. When an open approach was performed, several different approaches were used including: anterior, posterior, lateral and medial/lateral. Different pin configurations were also used, adding more heterogeneity to the studies (Table 4). Age and gender were well matched between the closed and open reduction groups within the different studies included (Table 1).

Table 1 Demographics of study articles retrieved and reviewed regarding closed versus open reduction

\begin{tabular}{|c|c|c|c|c|c|c|}
\hline Author & Year & LOE & \#patients & Approach & Age & Gender \\
\hline \multirow[t]{2}{*}{ 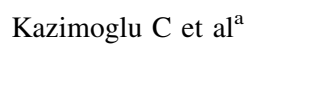 } & \multirow[t]{2}{*}{2009} & \multirow[t]{2}{*}{ III } & \multirow[t]{2}{*}{ CR: 43/OR:37 } & \multirow[t]{2}{*}{ Lateral } & CR: 6.5 years $(2-12)$ & CR: $29 \mathrm{M}-14 \mathrm{~F}$ \\
\hline & & & & & OR: 5.9 years $(2-12)$ & OR: $26 \mathrm{M}-11 \mathrm{~F}$ \\
\hline \multirow[t]{2}{*}{ Aktekin $\mathrm{CN}$ et $\mathrm{al}^{\mathrm{b}}$} & \multirow[t]{2}{*}{2008} & \multirow[t]{2}{*}{ III } & \multirow[t]{2}{*}{ CR: 32/OR:23 } & \multirow[t]{2}{*}{ Posterior } & CR: 8.1 years $(3-14)$ & CR: $20 \mathrm{M}-12 \mathrm{~F}$ \\
\hline & & & & & OR: 8.3 years $(5-12)$ & OR: $17 \mathrm{M}-6 \mathrm{~F}$ \\
\hline \multirow[t]{2}{*}{ Ozkoc $\mathrm{G}$ et $\mathrm{al}^{\mathrm{a}}$} & \multirow[t]{2}{*}{2004} & \multirow[t]{2}{*}{ III } & \multirow[t]{2}{*}{ CR: 55/OR:44 } & \multirow[t]{2}{*}{ Posterior } & CR: 7.6 years $(4-14)$ & CR: $30 \mathrm{M}-25 \mathrm{~F}$ \\
\hline & & & & & OR: 10.7 years $(3-15)$ & OR: $25 \mathrm{M}-19 \mathrm{~F}$ \\
\hline \multirow[t]{2}{*}{ Oh CW et $\mathrm{al}^{\mathrm{b}}$} & \multirow[t]{2}{*}{2003} & \multirow[t]{2}{*}{ III } & \multirow[t]{2}{*}{ CR: 21/OR:14 } & \multirow[t]{2}{*}{ Anterior } & CR: 6.7 years $(2-12)$ & CR: N/A \\
\hline & & & & & OR: 6.1 years $(3-11)$ & OR: N/A \\
\hline \multirow[t]{2}{*}{ Kaewpornsawan $\mathrm{K}$ et $\mathrm{al}^{\mathrm{a}}$} & \multirow[t]{2}{*}{2001} & \multirow[t]{2}{*}{ I } & \multirow[t]{2}{*}{ CR: 14/OR:14 } & \multirow[t]{2}{*}{ Lateral } & CR: 7.9 years $(5-11)$ & CR: $8 \mathrm{M}-6 \mathrm{~F}$ \\
\hline & & & & & OR: 6.8 years $(4.2-9.4)$ & OR: $11 \mathrm{M}-3 \mathrm{~F}$ \\
\hline Aronson DC et $\mathrm{al}^{\mathrm{b}}$ & 1993 & III & CR: 35/OR:11 & Anterior & CR + OR: 7 years $(3-13)$ & $\mathrm{CR}+\mathrm{OR}: 23 \mathrm{M}-23 \mathrm{~F}$ \\
\hline \multirow[t]{2}{*}{ Cramer KE et $\mathrm{al}^{\mathrm{b}}$} & \multirow[t]{2}{*}{1992} & \multirow[t]{2}{*}{ III } & \multirow[t]{2}{*}{ CR: 15/OR:14 } & \multirow[t]{2}{*}{$\mathrm{M}+\mathrm{L}: 12 \mathrm{px} / \mathrm{L}: 1$ px/P: 1 px. } & CR: 5.4 years $(2-8)$ & $\mathrm{CR}: 4 \mathrm{M}-11 \mathrm{~F}$ \\
\hline & & & & & OR: 6.2 years $(2-11)$ & OR: $5 \mathrm{M}-9 \mathrm{~F}$ \\
\hline
\end{tabular}

$C R$ closed reduction, $O R$ open reduction, N/A not data available

Approaches: $M$ medial, $L$ lateral, $P$ posterior

a Articles describing a comparison between a primary closed reduction attempt and a primary open reduction attempt

b Articles describing a comparison between a primary closed reduction attempt and a secondary open reduction attempt 
Table 2 Demographics of clinical study articles retrieved and reviewed regarding pin configurations

\begin{tabular}{llllll}
\hline Author & Year & \#Patients & Constructs & LOE \\
\hline Tripuraneni et al. & 2002 & 40 & 1L-1M (20 px) versus 2L or 3L (20 px) & II \\
Foead et al. & 2004 & 55 & $1 \mathrm{~L}-1 \mathrm{M}(33 \mathrm{px})$ versus 2L (32 px) & I \\
Kocher et al. & 2007 & 52 & $1 \mathrm{~L}-1 \mathrm{M}(24 \mathrm{px})$ versus 2L (28 px) & I \\
Ebenhardt et al. & a & 2007 & 83 & 2 cross lateral pins (69 px) versus 1L-1M (14 px) & III \\
Slongo et al. & 2008 & 31 & External Fixation (31 px) & IV \\
\hline
\end{tabular}

$1 L-1 M$ traditional cross-pin configuration (1 lateral pin and 1 medial pin), $2 L$ or $3 L$ two or three lateral pins, $L O E$ level of evidence

a A cross-pin configuration was used with a lateral approach

Table 3 Demographics of study articles retrieved and reviewed regarding effect of timing to surgery in complications

\begin{tabular}{lllll}
\hline Author & Year & \#Patients & $\begin{array}{l}\text { Cutoff time } \\
\text { (hours) }\end{array}$ & LOE \\
\hline Iyengar et al. & 1999 & E:23/D:35 & 8 & IV \\
Mehlman et al. & 2001 & E:52/D:146 & 8 & IV \\
Leet et al. $^{\text {a }}$ & 2002 & $158 \mathrm{pt}$ & N/A & IV \\
Gupta et al. & 2004 & E:50/D:100 & 12 & IV \\
Walmsley et al. & 2006 & E:126/D:45 & 8 & IV \\
\hline
\end{tabular}

$L O E$ level of evidence, $E$ early group (before cutoff time), $D$ delay group (after cutoff time)

${ }^{\text {a }}$ No cutoff time was used; a correlation coefficient was made

The outcome was assessed by Flynn's criteria [31] (Table 4). There was not a significant statistical difference found $(P>0.05)$ except in the ones dealing with a posterior approach $[1,6]$ in which a better functional as well as cosmetic results were found within the closed reduction group $(P<0.05)[1,6]$.

Time to union, ROM restriction, nerve injury, Baumann's angle difference and varus deformity were also assessed (Table 4). Aktekin et al. [6] found a statistically significant difference $(P=0.01)$ with regards to the time of union, being shorter in the closed reduction group (5.7 weeks vs. 7 weeks). ROM restriction was also statistically significantly lower $(P=0.03)$ within the closed reduction group $\left(3.8^{\circ} \mathrm{vs}\right.$. $12.3^{\circ}$ ); however, Kaewpornsawan et al. [2] didn't find any statistically significant difference. Five patients were found to have a transient ulnar nerve injury [1,3]; however, Cramer et al. [4] didn't find any iatrogenic nerve injury in their series. With regards to the Baumann's angle difference, a significant statistically difference was not found $[2,13](P>0.05$; Table 4). Aronson et al. [3] found a varus deformity in $5 / 35$ patients within the $\mathrm{CR}$ group and 1/11 within the OR group with no significant statistically difference.

Pin configurations

Three biomechanical studies were found [16-18]; they reported different results regarding rotational stability and torsional rigidity. Zionts et al. [16] found that the greatest resistance to rotation was achieved through a mediallateral cross-pinning configuration. On the other hand, Larson et al. [18] reported that three lateral pins configuration was equivalent to a cross-pin construct. Finally, Lee et al. [17] found the same torsional rigidity with a two lateral pin configuration or a cross-pinning construct.

There were two level I clinical studies included [19, 20], one level II [21], one level III [22] and one level IV [23]. Different constructs were used (traditional cross-pin configuration, two lateral pins, two lateral cross-pins and external fixator; Table 2). The outcome was assessed by Flynn's criteria, Baumann's angle and nerve injury (Table 5).

With regards to the Flynn's criteria, there was heterogeneity within the subcategories assessed. The functional subcategory was assessed in one article [21] and both categories in the remaining ones, but a global result was reported with no details regarding the distribution of patients according to the type of construct and outcome. The types of constructs compared were different. In three articles [19-21], a traditional cross-pin configuration was compared with a two lateral construct; a lateral cross-pinning configuration was compared with the traditional one [22] and in the remaining one an isolated external fixator without comparison was used [23]. Baumann's angle values were available in only three articles [19-21]. They were expressed either as an absolute value or [21] like a loss of angle $[19,20]$.

According to Flynn's criteria, regardless of the type of pin configuration used for stabilization of a displaced SCHF; there was not a statistically significant difference found $(P>0.05)$. The Baumann's angle as well as the Baumann's angle loss were not statistically different as described by Tripuraneni et al. [21] $(P>0.75)$, Foead et al. [19] $(P>0.74)$ and Kocher et al. [20] $(P>0.6)$, respectively. Nerve injury was described in ten patients $[19,21]$. In $80 \%$ of those cases, a traditional cross-pinning configuration was performed with no statistically significant difference $(P>0.05$ and $P>0.42$, respectively). 
Table 4 Outcome of study articles retrieved and reviewed regarding closed versus open reduction

\begin{tabular}{|c|c|c|c|c|c|}
\hline Author & Year & Approach & Pin configuration & Flynn's criteria & $\begin{array}{l}\text { Outcome other than Flynn's } \\
\text { criteria }\end{array}$ \\
\hline Kazimoglu et al. & 2009 & Lateral & $\begin{array}{l}\text { 2L: 11/1L-1M: } \\
\text { 11/2L-1M: } 15\end{array}$ & $\begin{array}{l}\text { Not statistically significant } \\
\text { difference }(P>0.05)\end{array}$ & $\begin{array}{l}\text { Outcomes of closed reduction } \\
\text { showed no superiority over open } \\
\text { reduction }\end{array}$ \\
\hline Aktekin et al. & 2008 & Posterior & 1L-1M: 55 & $\begin{array}{l}\text { Better functional and cosmetic } \\
\text { results into the closed reduction } \\
\text { group }(P<0.05)\end{array}$ & $\begin{array}{l}\text { Time to union: } \mathrm{CR}(5.7 \text { weeks })- \\
\text { OR }(7 \text { weeks })(P=0.01) . \mathrm{ROM} \\
\text { restriction: } \mathrm{CR}\left(3.8^{\circ}\right)-\mathrm{OR}\left(12.3^{\circ}\right) \\
(P=0.03)\end{array}$ \\
\hline Ozkoc et al. & 2004 & Posterior & 1L-1M: 99 & $\begin{array}{l}\text { Functional: } \mathrm{CR}(95 \% \\
\text { satisfactory)-OR }(71 \% \\
\text { satisfactory) }(P<0.05) \\
\text { Cosmetic: CR-OR }(95 \% \\
\text { satisfactory) }(P>0.05)\end{array}$ & $\begin{array}{l}\text { Two transient ulnar nerve injury in } \\
\text { each group }\end{array}$ \\
\hline Oh et al. & 2003 & Anterior & $\begin{array}{l}2 \mathrm{~L} \text { or } 3 \mathrm{~L}: 30 / 1 \mathrm{~L}- \\
1 \mathrm{M}: 5\end{array}$ & $\begin{array}{l}\text { Satisfactory results in both } \\
\text { groups }(P>0.05)\end{array}$ & $\begin{array}{c}\text { Baumann's angle difference: CR } \\
\left(8.7^{\circ}\right)-\mathrm{OR}\left(6.6^{\circ}\right)(P>0.05)\end{array}$ \\
\hline $\begin{array}{l}\text { Kaewpornsawan } \\
\text { et al. }\end{array}$ & 2001 & Lateral & 2L-1M: 28 & $\begin{array}{l}\text { CR: } 100 \% \text { excellent or good } \\
\text { results. OR: } 93 \% \text { excellent or } \\
\text { good results }(P>0.05)\end{array}$ & $\begin{array}{l}\text { Higher satisfaction score within } \\
\text { CR group/No differences in } \\
\text { ROM and Baumann's angle }\end{array}$ \\
\hline Aronson et al. & 1993 & Anterior & 1L-1M: 46 & $\begin{array}{l}\text { Similar functional and cosmetic } \\
\quad \text { results }(P>0.05)\end{array}$ & $\begin{array}{l}\text { Varus deformity: CR }(5 / 35)-\mathrm{OR} \\
(1 / 11) . \text { One transient ulnar nerve } \\
\text { injury in the CR group }\end{array}$ \\
\hline Cramer et al. & 1992 & $\begin{array}{l}\mathrm{M}+\mathrm{L}: 12 \mathrm{px} / \mathrm{L}: 1 \\
\text { px/P: } 1 \text { px. }\end{array}$ & N/A & $\begin{array}{l}\text { CR: } 93.3 \% \text { excellent or good } \\
\text { results. OR: } 85.71 \% \text { excellent or } \\
\text { good results }(P>0.05)\end{array}$ & No iatrogenic nerve injury \\
\hline
\end{tabular}

$C R$ closed reduction, $O R$ open reduction, $N / A$ not data available

Approaches: $M$ medial, $L$ lateral, $P$ posterior

$2 L$ two lateral, $1 L-1 M$ cross-pin, $2 L-1 M$ two lateral and one cross-medial, $3 L$ three lateral

Table 5 Outcome of clinical study articles retrieved and reviewed regarding pin configurations

\begin{tabular}{|c|c|c|c|c|c|}
\hline Author & Year & Flynn's criteria & Baumann's angle & Nerve injury & Statistical analysis $^{\mathrm{b}}$ \\
\hline $\begin{array}{l}\text { Tripuraneni } \\
\text { et al. }{ }^{\mathrm{a}}\end{array}$ & 2002 & $1 \mathrm{~L}-1 \mathrm{M}: 116^{\circ} / 2 \mathrm{~L}: 117^{\circ}$ & $\begin{array}{l}\text { 1L-1M: } 70.4^{\circ} \text { versus } \\
2 \mathrm{~L}: 71^{\circ}\end{array}$ & $\begin{array}{l}\text { 1L-1M: } 1 \text { versus } \\
\text { 2L: } 0\end{array}$ & $\begin{array}{r}\text { ROM: } P>0.25 \text {; Baumann's angle: } \\
P>0.75 \text {; Nerve injury: } P>0.05\end{array}$ \\
\hline Foead et al. & 2004 & $\begin{array}{l}\text { 1L-1M: } 89 \% \text { excellent-good } \\
\text { results. 2L: } 89 \% \text { excellent-good } \\
\text { results }\end{array}$ & $\begin{array}{l}\text { Angle loss: } 1 \mathrm{~L}-1 \mathrm{M} \text { : } \\
6^{\circ} \text { versus } 2 \mathrm{~L}: 5.3^{\circ}\end{array}$ & $\begin{array}{l}\text { 1L-1M: } 7 \text { versus } \\
\text { 2L: } 2\end{array}$ & $\begin{array}{l}\text { Flynn's criteria: } P>0.05 \text {; Baumann's } \\
\text { angle: } P>0.74 \text {; Nerve injury: } \\
P>0.42\end{array}$ \\
\hline $\begin{array}{l}\text { Kocher } \\
\text { et al. }\end{array}$ & 2007 & $\begin{array}{l}\text { 1L-1M: } 96 \% \text { excellent-good } \\
\text { results. 2L: } 96 \% \text { excellent-good } \\
\text { results }\end{array}$ & $\begin{array}{l}\text { Angle loss: } 1 \mathrm{~L}-1 \mathrm{M} \text { : } \\
5.4^{\circ} \text { versus } 2 \mathrm{~L}: 5.8^{\circ}\end{array}$ & 0 & $\begin{array}{l}\text { Flynn's criteria: } P>0.05 \text { Baumann's } \\
\text { angle: } P>0.6\end{array}$ \\
\hline $\begin{array}{l}\text { Ebenhardt } \\
\text { et al. }\end{array}$ & 2007 & $\begin{array}{l}2 \mathrm{~L} \text { (cross-pins): } 92 \% \text { excellent-good } \\
\text { results }\end{array}$ & N/A & 0 & Flynn's criteria: $P>0.05$ \\
\hline Slongo et al. & 2008 & $\begin{array}{l}\text { External fixator: } 96 \% \text { excellent- } \\
\text { good results }\end{array}$ & N/A & 0 & N/A \\
\hline
\end{tabular}

Pin configuration: $1 L-1 M$ traditional cross-pin configuration (1 lateral pin and 1 medial pin), $2 L$ or $3 L$ two or three lateral pins

${ }^{\text {a }}$ Functional outcome was reported based on range of elbow motion

b $P<0.05$ : Difference statistically significant

\section{Impact of time to surgery in complications}

All the articles included were level IV of evidence [24-28]. A total of 735 patients were included and classified according to the time to surgery (early treatment: 251 ; delay treatment: 326$)$. The study performed by Leet et al.
[26] was not included because a cutoff time was not used, instead, a correlation coefficient was calculated (Table 3 ). The cutoff time values used were $8 / 12 \mathrm{~h}$.

The need for an open reduction and neurovascular injury rate were used as outcome parameters. All the articles provided this data $[24,25,27,28]$ except the one conducted by Leet et al. [26]. 


\section{Open reduction rate}

For this analysis, three articles were included [24, 25, 28] with a total of 427 patients divided into two groups according to the time to surgery with a cutoff time of $8 \mathrm{~h}$ : early treatment (201 patients) versus delay treatment (226 patients). Articles were homogenous $(P=0.791)$ and an OR: 0.56 with a $95 \%$ confidential interval not statistically significant (Fig. 1a). Leet et al. [26] didn't find any correlation between an increased time from injury to surgical intervention and poor results. Gupta et al. [27] found a tendency of a higher rate of open reduction needed in patients with treatment after $12 \mathrm{~h}$ from injury (early treatment: $0 \%$ vs. delay treatment: $6 \%$ ), however, this difference was not statistically significant.

\section{Neurovascular injury}

Two articles were included for final statistical analysis $[25,28]$ with a total of 364 patients divided according to time to surgery with a cutoff time of $8 \mathrm{~h}$ in two groups: early treatment (173 patients) versus delay treatment (191 patients). Articles were homogeneous $(P=0.892)$ and an OR: 3.39 with a $95 \%$ confidential interval not statistically significant (Fig. 1b). Iyengar et al. [24] reported a 3\% rate within the delay treatment group $(P>0.05)$. On the other hand, Gupta et al. [27] found a 3\% rate within the early treatment group without statistically significant difference.

\section{Discussion}

Pediatric SCHF are very common injuries that all orthopaedic surgeons will probably encounter at some point in the emergency department; these fractures can be one of the most difficult to treat, it is the means by which this can be reliably and safely achieved that has caused some controversy.

The preferred approach on the management of displaced pediatric SCHF is closed reduction and percutaneous
Fig. 1 Forest plot of early versus delayed time to surgery in complications (open reduction and nerve injury rates). $I^{2}$ was used to assess heterogeneity among the studies included in the analysis with a $P<0.05$ being statistically significant. Odds ratios $(O R)$ were also used with a $95 \%$ confidential interval. a Forest plot of early versus delayed time to surgery in open reduction rate. There were no heterogeneity among the studies included with a $P=0.791$ $(P>0.05)$ and an $\mathrm{OR}=0.56$ (below 1) didn't demonstrate an increased risk of open reduction with delay surgery. It was not statistically significant because the CI contains $1(0.01,57.10)$. b Forest plot of early versus delayed time to surgery in nerve injury rate. There were no heterogeneity among the studies included with a $P=0.892$ $(P>0.05)$ and an $\mathrm{OR}=3.56$ (above 1) demonstrates increase risk of iatrogenic neurological injury with early surgery. It was not statistically significant because the CI contains 1 $(0.01,1.55)$
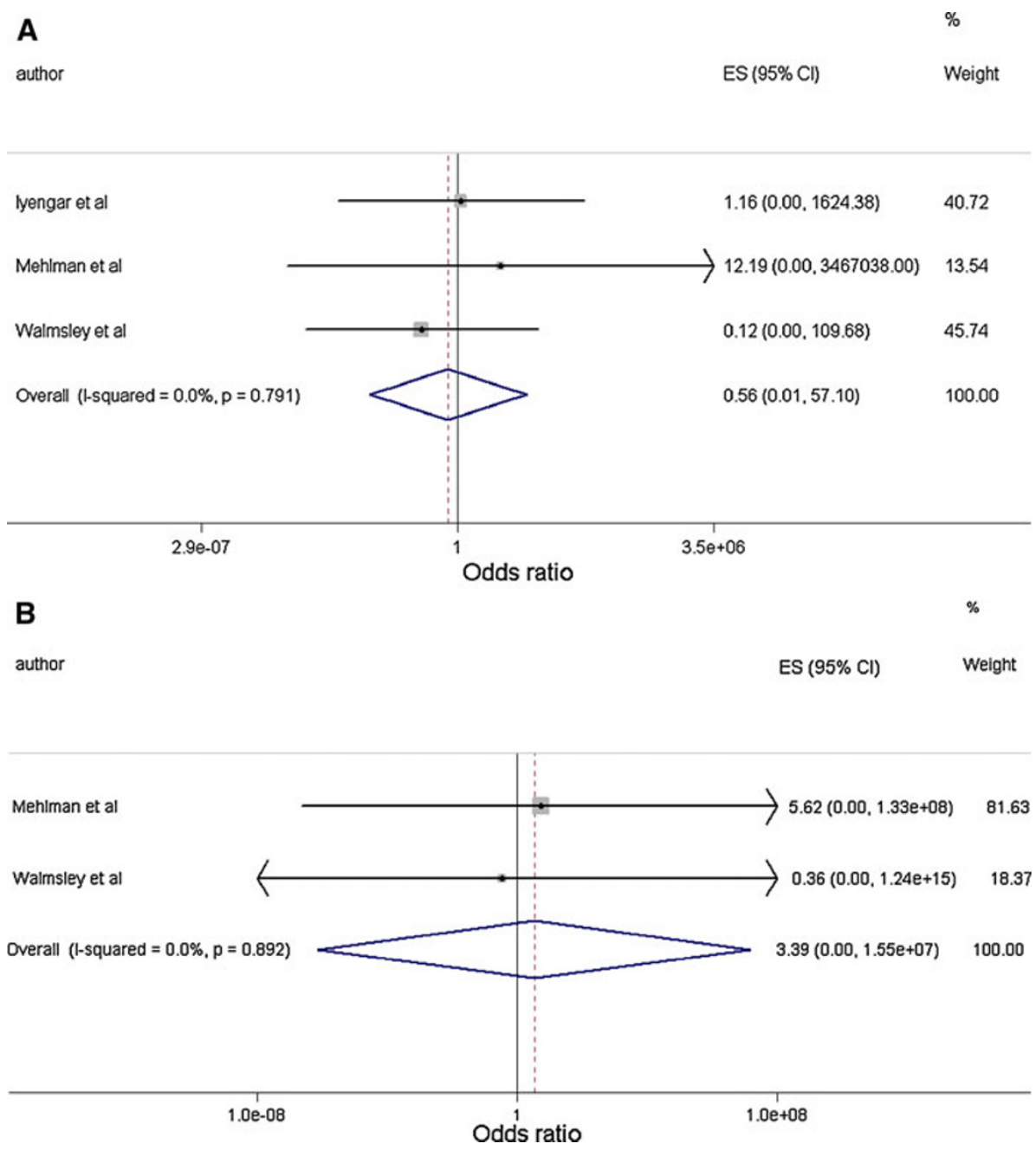
pinning [14, 32, 33]; however, this technique requires experience and it is not free of complications or incomplete success.

Inadequate reduction in the coronal plane could produce deformities such as cubitus varus. Functional losses could be due to malrotation, angulation, or translation in the sagittal plane [28]. In this sense, that due to these potential issues, open reduction and pinning gain a place within the treatment of these fractures.

There are several studies regarding the method of reduction used (Table 1), being important to bear in mind their heterogeneity because doing so, a comparison directly with a primary open reduction could show us a better view of its real effect on outcome and complications due to the avoidance of potential fractures with more difficult patterns $[1,9]$. There were no significant statistically differences among the studies included according to Flynn's criteria; except when a posterior approach was used regardless of an open reduction was performed in a primary or secondary fashion. The findings reported by Aktekin et al. [6] as well as Ozkoc et al. [1], could be explained based on the fact that, through a posterior approach; anterior structures such as the brachialis muscle as well as neurovascular structures could not be achieved and the effect of a retracted scar localized posteriorly could decrease the range of motion $[5,6]$. Time to union seems to be faster when a closed reduction is performed [6] (Table 4); this could be explained by not disrupting the fracture hematoma; however, this fact is not supported by other studies. Neurologic injury is another complication that should be taken into account; there were only five patients reported with an ulnar nerve injury (CR:3; OR:2), we think this is not an important difference in addition to the fact that in $86-100 \%$ of cases the recovery is spontaneous, even though, this could happen some months after injury [34].

Our recommendation based on the findings presented within these articles, is that unless a specific indication for open reduction is present, we should always do a closed reduction attempt first. If a satisfactory reduction has not been achieved with closed reduction, an open reduction and pinning technique should be performed [5].

Pin constructs used for stabilization of these fractures are under debate because, even though, an anatomical reduction is achieved; due to the width of the distal humerus that ranges between 2 and $3 \mathrm{~mm}$, a rotational stable construct is difficult to perform.

Outcomes between biomechanical studies [16-18] and clinical studies [19-23] are not comparable due to the different parameters used. Biomechanical studies studied torsional rigidity as well as rotational stability and their results not necessarily had a clinical correlation.

Three articles made a comparison between a mediallateral construct and two lateral configuration [19-21] regarding Flynn's criteria. There was not a difference in functional as well as cosmetic subcategories, with $89-96 \%$ of excellent-good results. Ebenhardt et al. [22] recently has proposed a different construct characterized by a cross-pin configuration through a lateral approach with $92 \%$ of excellent-good results. We think this is an interesting alternative to avoid iatrogenic nerve injury. Slongo et al. [23] described the usage of a lateral external fixator to stabilize SCHF. Their results were excellent or good in all cases except one. This is based on the compression of the lateral column, which would secondarily prevent medial column collapse. This could be a safe alternative for some difficult unstable Gartland type III SCHF.

The difference in the absolute value of the Baumann's angle as well as the angle loss is not statistically significant regardless the pin configuration used for stabilization. This could be explained because this is more related to the accuracy of reduction than the pin configuration [35].

A iatrogenic neurological injury rate between 2 and $6 \%$ has been reported [36-38] being the ulnar nerve the most frequently nerve affected due to the usage of medial $\mathrm{K}$-wires. This finding has made the cross-pinning configuration a less popular construct among some orthopedic surgeons. Among the studies that compared a cross-pin configuration with a two lateral pin construct [19-21], there was not a statistically significant difference found. To avoid nerve injury during a medial pin insertion, we recommend to identify the ulnar nerve through a small incision. With a two lateral pin construct, nerve injury could be explained by a hyperflexion of the elbow during the procedure so we should be aware of this to prevent this issue. We think this should not be an issue when choosing a construct for stabilization of these types of fractures.

The effect of time to surgery of a displaced SCHF in complications is a controversial topic. Classically, a displaced SCHF should be reduced and pinned emergently, but some authors think that can be treated in a delayed fashion without the risk of increasing complications.

Arguments for early surgical treatment include easy of fracture reduction, and decrease in neurovascular complications, ischemic contracture, angular deformity and elbow stiffness. Disadvantages to reducing fractures emergently include fatigue of the physician during the night, as well as the experience of the surgeon in charge that may be a general orthopedic surgeon.

Open reduction needed and iatrogenic neurological injury were assessed through the articles included. According to our findings, delay to surgery doesn't increase open reduction probability (OR: 0.59), as observed by other authors [24-27], however, if a significant swelling at presentation and delay in fracture reduction is present, these could be an important warning signs for the 
development of a compartment syndrome [36] with its devastating consequences if not treated on time. On the other hand, in one of the articles included [28], a statistically significant difference was found in favor of an increase rate of open reduction when a delay in surgery was present (E/11\% vs. D: $33 \% ; P>0.05)$. We think that if there are no signs of a possible complication such as compartment syndrome or a vascular issue (pulseless supracondylar humerus fracture), a delay in the definitive treatment could be assumed if there are not the adequate conditions for surgery.

There is a tendency of an increased probability with an early time to surgery (OR: 3.39 ) to develop an iatrogenic neurological injury, however, this finding is not statistically significant. We think this is more related with the type of pin configuration used for stabilization as well as the soft tissue status that could made more difficult to identify the ulnar nerve.

Limitations within our study must be acknowledged. The majority of articles were heterogeneous with regard to their outcomes; however, we feel that some recommendations could be made. We have to take into account that fractures treated under a secondary open reduction attempt could be more serious than the ones treated with a closed reduction attempt, this should be bear in mind when interpreting the results regarding closed versus open reduction methods. When interpreting results of pin configuration articles, we have to consider the different outcomes assessed within the biomechanical as well as the clinical studies and bear in mind the different levels of evidence.

\section{Conclusions}

Based on our findings, some recommendations can be done:

1. Anatomic reduction is one of the aims in the management of displaced SCHF, is in this sense that, unless a specific indication for open reduction is present, a closed reduction attempt should always be done first. If it fails, then an open reduction could be performed.

2. There is no difference in clinical studies between different constructs used for stabilization of these fractures. We think that it is more important to engage both columns as well as divergence of the pins no matter whatever configuration is applied.

3. The new methods for stabilization are promising but suitable only in specific cases. We emphasize the idea of following the principles mention above for obtaining a stable construct.

4. There is a tendency in the literature that in children without progressive neurological deficits and vascular compromise, the time to surgery is not an important factor to increase the risk of complications as well as open reduction rate. We think that under these circumstances, surgery should be done with the best conditions for the patient and the surgeon no matter if some delay occurs.

5. In the majority of cases, neurological injuries present a spontaneous recovery.

Acknowledgments The authors thanks Eva María Andrés Esteban for her contribution with the statistical analysis and creation of graphs.

Disclaimer The authors did not receive any outside funding or grants in support of their research for or preparation of this work. No commercial entity paid or directed, or agreed to pay or direct, any benefits to any research fund, foundation, division, center, clinical practice, or other charitable or nonprofit organization with which the authors, or a member of their immediate families, are affiliated or associated.

Open Access This article is distributed under the terms of the Creative Commons Attribution License which permits any use, distribution and reproduction in any medium, provided the original author(s) and source are credited.

\section{References}

1. Ozkoc G, Gonc U, Kayaalp A, Teker K, Peker TT (2004) Displaced supracondylar humeral fractures in children: open reduction vs. closed reduction and pinning. Arch Orthop Trauma Surg 124(8):547-551

2. Kaewpornsawan K (2001) Comparison between closed reduction with percutaneous pinning and open reduction with pinning in children with closed totally displaced supracondylar humeral fractures: a randomized controlled trial. J Pediatr Orthop B 10(2):131-137

3. Aronson DC, Van Vollenhoven E, Meeuwis JD (1993) K-wire fixation of supracondylar humeral fractures in children: results of open reduction via a ventral approach in comparison with closed treatment. Injury 24(3):179-181

4. Cramer KE, Devito DP, Green NE (1992) Comparison of closed reduction and percutaneous pinning versus open reduction and percutaneous pinning in displaced supracondylar fractures of the humerus in children. J Orthop Trauma 6(4):407-412

5. Pretell Mazzini J, Rodriguez Martin J, Andres-Esteban EM (2010) Surgical approaches for open reduction and pinning in severely displaced supracondylar humerus fractures in children: a systematic review. J Child Orthop 4(2):143-152

6. Aktekin CN, Toprak A, Ozturk AM, Altay M, Ozkurt B, Tabak AY (2008) Open reduction via posterior triceps sparing approach in comparison with closed treatment of posteromedial displaced Gartland type III supracondylar humerus fractures. J Pediatr Orthop B 17(4):171-178

7. Omid R, Choi PD, Skaggs DL (2008) Supracondylar humeral fractures in children. J Bone Joint Surg Am 90(5):1121-1132

8. Otsuka NY, Kasser JR (1997) Supracondylar fractures of the humerus in children. J Am Acad Orthop Surg 5(1):19-26

9. Kazimoglu C, Cetin M, Sener M, Agus H, Kalanderer O (2009) Operative management of type III extension supracondylar fractures in children. Int Orthop 33(4):1089-1094 
10. Battaglia TC, Armstrong DG, Schwend RM (2002) Factors affecting forearm compartment pressures in children with supracondylar fractures of the humerus. J Pediatr Orthop 22(4): 431-439

11. Gartland JJ (1959) Management of supracondylar fractures of the humerus in children. Surg Gynecol Obstet 109(2):145-154

12. Sadiq MZ, Syed T, Travlos J (2007) Management of grade III supracondylar fracture of the humerus by straight-arm lateral traction. Int Orthop 31(2):155-158

13. Oh CW, Park BC, Kim PT, Park IH, Kyung HS, Ihn JC (2003) Completely displaced supracondylar humerus fractures in children: results of open reduction versus closed reduction. J Orthop Sci 8(2):137-141

14. Mulhall KJ, Abuzakuk T, Curtin W, O'Sullivan M (2000) Displaced supracondylar fractures of the humerus in children. Int Orthop 24(4):221-223

15. Sibly TF, Briggs PJ, Gibson MJ (1991) Supracondylar fractures of the humerus in childhood: range of movement following the posterior approach to open reduction. Injury 22(6):456-458

16. Zionts LE, McKellop HA, Hathaway R (1994) Torsional strength of pin configurations used to fix supracondylar fractures of the humerus in children. J Bone Joint Surg Am 76(2):253-256

17. Lee SS, Mahar AT, Miesen D, Newton PO (2002) Displaced pediatric supracondylar humerus fractures: biomechanical analysis of percutaneous pinning techniques. J Pediatr Orthop 22(4): 440-443

18. Larson L, Firoozbakhsh K, Passarelli R, Bosch P (2006) Biomechanical analysis of pinning techniques for pediatric supracondylar humerus fractures. J Pediatr Orthop 26(5):573-578

19. Foead A, Penafort R, Saw A, Sengupta S (2004) Comparison of two methods of percutaneous pin fixation in displaced supracondylar fractures of the humerus in children. J Orthop Surg (Hong Kong) 12(1):76-82

20. Kocher MS, Kasser JR, Waters PM, Bae D, Snyder BD, Hresko MT et al (2007) Lateral entry compared with medial and lateral entry pin fixation for completely displaced supracondylar humeral fractures in children. A randomized clinical trial. J Bone Joint Surg Am 89(4):706-712

21. Tripuraneni KR, Bosch PP, Schwend RM, Yaste JJ (2009) Prospective, surgeon-randomized evaluation of crossed pins versus lateral pins for unstable supracondylar humerus fractures in children. J Pediatr Orthop B 18(2):93-98

22. Eberhardt O, Fernandez F, Ilchmann T, Parsch K (2007) Cross pinning of supracondylar fractures from a lateral approach. Stabilization achieved with safety. J Child Orthop 1(2):127-133

23. Slongo T, Schmid T, Wilkins K,Joeris A (2008) Lateral external fixation-a new surgical technique for displaced unreducible supracondylar humeral fractures in children. J Bone Joint Surg Am 90(8):1690-1697
24. Iyengar SR, Hoffinger SA, Townsend DR (1999) Early versus delayed reduction and pinning of type III displaced supracondylar fractures of the humerus in children: a comparative study. J Orthop Trauma 13(1):51-55

25. Mehlman CT, Strub WM, Roy DR, Wall EJ, Crawford AH (2001) The effect of surgical timing on the perioperative complications of treatment of supracondylar humeral fractures in children. J Bone Joint Surg Am 83-A(3):323-327

26. Leet AI, Frisancho J, Ebramzadeh E (2002) Delayed treatment of type 3 supracondylar humerus fractures in children. J Pediatr Orthop 22(2):203-207

27. Gupta N, Kay RM, Leitch K, Femino JD, Tolo VT, Skaggs DL (2004) Effect of surgical delay on perioperative complications and need for open reduction in supracondylar humerus fractures in children. J Pediatr Orthop 24(3):245-248

28. Walmsley PJ, Kelly MB, Robb JE, Annan IH, Porter DE (2006) Delay increases the need for open reduction of type-III supracondylar fractures of the humerus. J Bone Joint Surg Br 88(4): $528-530$

29. Sackett DL (1986) Rules of evidence and clinical recommendations on the use of antithrombotic agents. Chest 89(2 Suppl):2S-3S

30. Higgins JP, Thompson SG (2002) Quantifying heterogeneity in a meta-analysis. Stat Med 21(11):1539-1558

31. Flynn JC, Matthews JG, Benoit RL (1974) Blind pinning of displaced supracondylar fractures of the humerus in children. Sixteen years' experience with long-term follow-up. J Bone Joint Surg Am 56(2):263-272

32. Ay S, Akinci M, Kamiloglu S, Ercetin O (2005) Open reduction of displaced pediatric supracondylar humeral fractures through the anterior cubital approach. J Pediatr Orthop 25(2):149-153

33. Mazda K, Boggione C, Fitoussi F, Pennecot GF (2001) Systematic pinning of displaced extension-type supracondylar fractures of the humerus in children. A prospective study of 116 consecutive patients. J Bone Joint Surg Br 83(6):888-893

34. Ramachandran M, Birch R, Eastwood DM (2006) Clinical outcome of nerve injuries associated with supracondylar fractures of the humerus in children: the experience of a specialist referral centre. J Bone Joint Surg Br 88(1):90-94

35. Chess DG, Leahey JL, Hyndman JC (1994) Cubitus varus: significant factors. J Pediatr Orthop 14(2):190-192

36. Ramachandran M, Birch R, Eastwood DM (2008) Delaying treatment of supracondylar fractures in children: has the pendulum swung too far? J Bone Joint Surg Br 90(9):1228-1233

37. Rasool MN, Naidoo KS (1999) Supracondylar fractures: posterolateral type with brachialis muscle penetration and neurovascular injury. J Pediatr Orthop 19(4):518-522

38. Birch R, Achan P (2000) Peripheral nerve repairs and their results in children. Hand Clin 16(4):579-595 